\title{
Controlled Comparison of Two Anxiolytic Benzodiazepines, Cloxazolam and Bromazepam
}

\author{
Marc Ansseau, Remy von Frenckell \\ Psychiatric Unit, Centre Hospitalier Universitaire du Sart Tilman, Liège, Belgium
}

Key Words. Cloxazolam - Bromazepam - Benzodiazepines $\cdot$ Anxiolytic $\cdot$ Anxiety

\begin{abstract}
The clinical activity and the tolerance of cloxazolam ( $4 \mathrm{mg} /$ day), a new anxiolytic benzodiazepine, was compared to bromazepam ( $12 \mathrm{mg} /$ day) in two parallel groups of 427 and 410 psychiatric outpatients, respectively. The duration of the study was 4 weeks with clinical assessments at inclusion and after 2 and 4 weeks of therapy by the Hamilton anxiety scale and visual analogue scales. While the Hamilton anxiety scale did not exhibit significant differences between the two benzodiazepines, visual analogue scales showed significant superiority of cloxazolam over bromazepam on psychological anxiety, somatic anxiety, depressed mood, and sleep, with a lack of significant difference related to the sedative effect, but less muscle-relaxant effect with cloxazolam than with bromazepam. The better efficacy and tolerance of cloxazolam compared to bromazepam was confirmed by the global assessments using visual analogue scales; moreover, a significantly larger proportion of patients in the cloxazolam group wanted to continue the same treatment.
\end{abstract}

\section{Introduction}

Cloxazolam is a benzodiazepine derivative characterized by a closed furane ring. After oral administration, chloro-N-demethyldiazepam, which represents the main active metabolite, appears in plasma after a mean lag time of $0.9 \mathrm{~h}$ and reaches its peak level within $3 \mathrm{~h}$, with a mean elimination half-life of $65.9 \mathrm{~h}$ [Lavene et al., 1980]. In animals, cloxazolam appears to be more potent than diazepam in most tests predictive of an anxiolytic activity, while its sedative and muscle-relaxant properties appear to be less pronounced [Kamioka et al., 1972]. The anxiolytic activity of cloxazolam has been demonstrated in several double-blind comparisons with placebo or reference benzodiazepines such as lorazepam and diazepam [Fischer-Cornelssen, 1981; Zmorski and Fischer-Cornelssen, 1985]. No study, however, has compared cloxazolam with bromazepam, another anxiolytic benzodiazepine with an excellent profile of efficacy and tolerance [Fontaine et al., 1983, 1985]. Therefore, the purpose of the present trial was to compare the anxiolytic activity and the tolerance of cloxazolam with bromazepam and to try to specify possible differences in the clinical profile of the two benzodiazepines.

\section{Methods}

\section{Study Design}

The study compared under double-blind conditions two parallel grous of anxious outpatients receiving either cloxazolam at an initial dose of $4 \mathrm{mg} /$ day ( $1 \mathrm{mg}$ in the morning, $1 \mathrm{mg}$ at noon, and $2 \mathrm{mg}$ at bedtime) or bromazepam at an initial dose of $12 \mathrm{mg} /$ day ( $3 \mathrm{mg}$ in the morning, $3 \mathrm{mg}$ at noon, and $6 \mathrm{mg}$ at bedtime). The duration of the study was 4 weeks with assessments at baseline and after 2 and 4 weeks of treatment. The initial dose could be adápted after 2 weeks of treatment according to both efficacy and tolerance with a maximal daily dose of $8 \mathrm{mg}$ for cloxazolam and $24 \mathrm{mg}$ for bromazepam. Other anxiolytic and hypnotic benzodiazepines were excluded throughout the study period. Finally, the protocol was approved by the Ethical Committee of Liège Medical School and all patiens gave their informed consent. 
Table 1. Comparison of age and baseline ratings in patients treated with cloxazolam or bromazepam (mean and SD)

\begin{tabular}{|c|c|c|c|c|c|c|c|}
\hline & & \multicolumn{2}{|c|}{$\begin{array}{l}\text { Cloxazolam group } \\
(\mathrm{n}=427)\end{array}$} & \multicolumn{2}{|c|}{$\begin{array}{l}\text { Bromazepam group } \\
(n=410)\end{array}$} & \multirow[t]{2}{*}{$\mathrm{F}$} & \multirow[t]{2}{*}{$\mathrm{p}$} \\
\hline & & mean & SD & mean & SD & & \\
\hline , & & 43.53 & 12.80 & 42.94 & 12.90 & 0.42 & NS \\
\hline Hamilton anxiety score & & 26.70 & 8.03 & 26.48 & 8.30 & 0.16 & NS \\
\hline \multirow[t]{4}{*}{ Visual analogue scales, $\mathrm{mm}$} & psychological anxiety & 67.80 & 12.77 & 68.45 & 19.25 & 0.23 & NS \\
\hline & somatic anxiety & 60.48 & 23.22 & 59.85 & 24.21 & 0.14 & NS \\
\hline & insomnia & 50.05 & 27.53 & 48.06 & 28.51 & 1.05 & NS \\
\hline & depressed mood & 47.13 & 26.46 & 48.48 & 26.92 & 0.53 & NS \\
\hline
\end{tabular}

Table 2. Comparison of the clinical profiles of cloxazolam and bromazepam assessed by visual analogue scales (mean and SD)

\begin{tabular}{|c|c|c|c|c|c|c|c|}
\hline & & \multicolumn{2}{|c|}{$\begin{array}{l}\text { Cloxazolam group } \\
(\mathrm{n}=427)\end{array}$} & \multicolumn{2}{|c|}{$\begin{array}{l}\text { Bromazepam group } \\
(n=410)\end{array}$} & \multirow[t]{2}{*}{$\mathrm{F}$} & \multirow[t]{2}{*}{$\mathrm{p}$} \\
\hline & & mean & SD & mean & SD & & \\
\hline \multirow{6}{*}{ After 2 weeks } & effect on psychological anxiety & 57.08 & 24.54 & 53.45 & 25.48 & 4.29 & 0.04 \\
\hline & effect on somatic anxiety & 53.99 & 25.09 & 53.23 & 25.38 & 0.16 & NS \\
\hline & effect on sleep & 51.96 & 29.47 & 47.84 & 29.19 & 3.91 & 0.05 \\
\hline & effect on depressed mood & 38.50 & 27.13 & 34.71 & 25.26 & 4.05 & 0.05 \\
\hline & daytime sedative effect & 28.20 & 26.05 & 31.27 & 27.04 & 2.71 & NS \\
\hline & muscle-relaxant effect & 21.27 & 20.06 & 23.14 & 22.38 & 1.57 & NS \\
\hline \multirow{6}{*}{ After 4 weeks } & effect on psychological anxiety & 66.05 & 23.24 & 62.66 & 24.01 & 3.80 & 0.05 \\
\hline & effect on somatic anxiety & 64.31 & 24.35 & 60.31 & 25.11 & 4.82 & 0.03 \\
\hline & effect on sleep & 58.16 & 30.16 & 54.29 & 29.14 & 2.59 & 0.10 \\
\hline & effect on depressed mood & 42.69 & 29.31 & 38.47 & 27.60 & 3.98 & 0.05 \\
\hline & daytime sedative effect & 25.71 & 23.98 & 28.29 & 25.03 & 2.06 & NS \\
\hline & muscle-relaxant effect & 19.06 & 18.91 & 22.42 & 21.17 & 5.14 & 0.02 \\
\hline
\end{tabular}

\section{Assessments}

The initial assessment collected historical, demographic, medical, and clinical data. The baseline evaluation of anxiety symptoms was performed by the Hamilton [1959] anxiety scale as well as by four $100-\mathrm{mm}$ visual analogue scales rating specifically the level of psychological anxiety, somatic anxiety, insomnia, and depressed mood from none to maximal. The subsequent evaluations included the Hamilton anxiety scale and a battery of six $100-\mathrm{mm}$ visual analogue scales rating the effect of the treatment on psychological anxiety, somatic anxiety, sleep, depressed mood, as well as the daytime sedative and muscle-relaxant effects. All those variables were extracted from a 'star' model designed to differentiate the clinical profile of benzodiazepines [Ansseau et al., 1984b]. The final assessment also included a global assessment of efficacy and tolerance by two $100-\mathrm{mm}$ visual analogue scales as well as the desire to pursue the same treatment.

\section{Subjects}

One hundred and thirty-four Belgian psychiatrists included a total of 837 patients between April and July 1989. A training session with all psychiatrists was organized where all rating instruments were explained and tested in order to ensure a good interrater reliability. All subjects were anxious outpatients who, in the opinion of the psychiatrist, would benefit from an anxiolytic benzodiazepine. The sample comprised 323 male patients and 514 female patients, with age ranging from 19 to 76 years, and a mean age (SD) of 43.20 (12.85). Patients with previous hypersensitivity to benzodiazepines, with current alcohol or drug abuse, with myasthenia or incompensated respiratory failure as well as women who were pregnant, lactating or without adequate contraceptive methods were excluded from the study.

\section{Data Analysis}

Baseline data in the two subgroups were compared by two-way analysis of variance (ANOVA) or by chi-square statistics. The relationship between the variability in Hamilton anxiety scale baseline scores from each of the 134 centers and the magnitude of the drug effects measured, tested using a three-way ANOVA (center, drug, time), showed nonsignificant results: $F(133,748)=0.12$. The results of the treatment were then compared by two-way ANOVA, ANOVA with repeated measures, or chi-square statistics. All procedures used the SAS package. 


\section{Results}

\section{Baseline Data}

The cloxazolam group comprised 427 patients and the bromazepam group 410 patients, without significant differences in the gender distribution: $36.5 \%$ were men and $63.5 \%$ were women in the cloxazolam group and $40.8 \%$ were men and $59.2 \%$ were women in the bromazepam group (chi square $=1.63$, d.f. $=1, p=N S$ ). Age as well as baseline severity in all ratings did not differ between the two treatment groups (table 1).

\section{Dropouts}

A total of $18.0 \%$ of cloxazolam-treated patients and $18.0 \%$ of bromazepam-treated patients left the study before completion (chi square $=0.006$, d.f. $=1, p=N S$ ) for inefficacy $(4.2 \%$ with cloxazolam and $3.5 \%$ with bromazepam), side effects, mainly drowsiness ( $4.5 \%$ with cloxazolam and $5.8 \%$ with bromazepam), or for reasons unrelated to the treatment $(9.3 \%$ with cloxazolam and $8.7 \%$ with bromazepam).

\section{Hamilton Anxiety Scale}

The comparison of changes over time in mean Hamilton anxiety scores did not show significant differences between cloxazolam and bromazepam: $F(1,748)=3.59$, $\mathrm{p}=0.058$ (fig. 1). This lack of significant differences was also noted in the evolution of psychic and somatic factors $[F(1,754)=1.69$ and 1.86 , respectively $]$ as well as of all individual items.

\section{Visual Analogue Scales}

The comparison of the clinical profile of cloxazolam and bromazepam by visual analogue scales showed significant therapeutic superiority of cloxazolam over bromazepam on psychological anxiety both after 2 and 4 weeks $(p=0.04 \text { and } 0.05)^{\prime}$, on somatic anxiety after 4 weeks $(p=0.05)$, on sleep after 2 weeks $(p=0.05)$ and on depressed mood after 2 and 4 weeks $(p=0.05$ and 0.05 ; table 2). In contrast, bromazepam exhibited significantly more muscle-relaxant activity after 4 weeks of treatment $(\mathrm{p}=0.02 ;$ table 2$)$.

\section{Global Assessment}

The global assessment of efficacy and tolerance by visual analogue scales showed significant superiority of cloxazolam over bromazepam: for efficacy, 67.34 (23.37) vs. $62.94(24.71), F(1,761)=6.40, p=0.01$ and for tolerance, $75.64(21.47)$ vs. $72.18(23.44), F(1,753)=$ $4.50, p=0.03$. Moreover, the desire to pursue the same

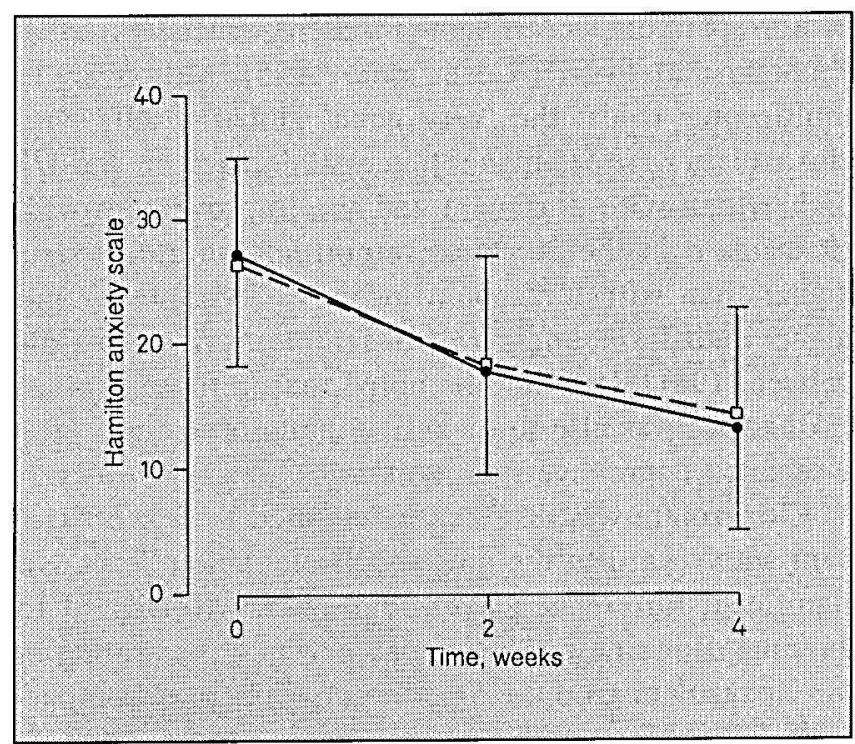

Fig. 1. Changes over time in mean ( \pm SD) Hamilton anxiety scores in patients treated with cloxazolam $(n=427)$ or bromazepam $(\mathrm{n}=410) . \bullet=$ Cloxazolam; $\square-\neg \square=$ bromazepam.

treatment was higher in cloxazolam-treated patients than in bromazepam-treated patients: 79.1 vs. $70.7 \%$, chi square $=6.93$, d.f. $=1, p=0.008$.

\section{Dosage}

The mean number (SD) of tablets (cloxazolam $=2 \mathrm{mg}$, bromazepam $=6 \mathrm{mg}$ ) taken at the end of the study was $0.61(0.27)$ in the morning, $0.58(0.29)$ at noon, and 1.05 $(0.37)$ in the evening in the cloxazolam group, and 0.60 (0.27) in the morning, $0.59(0.31)$ at noon, and 1.04 (0.35) in the evening in the bromazepam group, indicating a lack of significant difference at any time of the day ( $F=0.05,0.01$, and 0.06 , respectively).

\section{Discussion}

The results of the present study suggest better efficacy and tolerance of cloxazolam as compared to bromazepam. The difference in efficacy is marked not only in anxiety symptoms, as assessed by the visual analogue scales related to psychological and somatic anxiety, but also in insomnia and associated depressive symptomatology, as assessed by the specific visual analogue scales. The anxiolytic activity of cloxazolam had previously been demonstrated in double-blind comparisons with placebo as well as reference benzodiazepines, such 
as diazepam and lorazepam [Fischer-Cornelssen, 1981; Zmorski and Fischer-Cornelssen, 1985]. Moreover, in multicenter trials, the 'very good' global results with cloxazolam were $1 / 5$ higher than with lorazepam and $1 / 3$ higher than with diazepam and the improvement with cloxazolam in the 20 'most important symptoms' was higher than with lorazepam in $55 \%$ of symptoms and higher than diazepam in $95 \%$ of symptoms [Fischer-Cornelssen, 1981]. It should be noted that in those studies, cloxazolam was also more active than diazepam on the associated depressive symptomatology.

Cloxazolam was also better tolerated than bromazepam with regard to the muscle-relaxant side effects. No significant difference existed, however, with rêgard to daytime drowsiness, despite a somewhat lower rating in the cloxazolam group. However, a recent study comparing reaction time and recognition time in anxious patients treated by cloxazolam or bromazepam showed different patterns of changes: after 4 weeks of treatment, cloxazolam improved the speed of processing information and motor response from baseline value while bromazepam induced the opposite effect [Figueira et al., 1987].

Studies demonstrating statistically significant differences between active benzodiazepines are very infrequent in the literature [review in Ansseau et al., 1985] and several authors assume that all benzodiazepines are equivalent in terms of efficacy and tolerance and that the only differences depend on the relative potency and pharmacokinetics of benzodiazepine derivatives [Kesson et al., 1976; Sellers, 1978; Bellantuono et al., 1980]. Several arguments support our finding of an actual difference between cloxazolam and bromazepam rather than a failure to select equivalent doses. First, cloxazolam tends to be superior to bromazepam in both efficacy and tolerance. A better efficacy could depend on a too high dose selected as compared to the reference compound but would be responsible for more side effects. Second, the number of tablets used in the two groups at the end of the treatment period did not differ by more than 0.01 unit whereas it could be adapted according to both efficacy and tolerance, suggesting that cloxazolam $2 \mathrm{mg}$ and bromazepam $6 \mathrm{mg}$ are fairly equivalent.

The lack of a requirement of standardized diagnoses for inclusion in this study can be considered as a weakness. Our purpose was, however, to use a more 'naturalistic' design testing the benzodiazepines without prerequired diagnosis. Indeed, benzodiazepines are prescribed in a much larger patient population than defined in DSM-III-R 'generalized anxiety disorder'. This diagnostic category with all its requirements and particularly the need for a 6-month minimal length of pathology is far from the actual use of benzodiazepine anxiolytics. It should be emphasized that in clinical practice, psychiatrists use benzodiazepines without particular reference to DSM-III diagnoses, but according to clinical symptomatology.

The demonstration of clinical differences between active benzodiazepines in our study may depend on several factors. First, the large number of patients included markedly increases the statistical power. Second, the visual analogue scales designed for this trial are very sensitive to demonstate subtle differences. They are easy for the subjects to grasp, quick to fill out and, as the rater is not restricted to direct quantitative terms, permit as fine a discrimination as she/he wishes [Bond and Lader, 1974; Ansseau et al., 1984a]. In addition, they reduce the difficulties of response sets and the artificial distribution of positive and negative responses [Aitken, 1969]. Third, all patients selected for this study were referred to psychiatrists for their anxious symptomatology; this increases the homogeneity of the sample and limits the placebo effect, particularly important in anxious patients treated in general practice [Wheatley, 1982].

The significant superiority of cloxazolam over bromazepam in the proportion of patients who showed a desire to continue the same treatment can be interpreted as reflecting better efficacy and tolerance. An alternative explanation could be that cloxazolam exhibits an increased tendency for the development of dependence and abuse. It should be noted, however, that the desire to pursue the same treatment was strictly correlated with the data on efficacy and side effects. Moreover, the potential for abuse and dependence of cloxazolam seems rather low, as reported in a long-term study where patients underwent regular placebo-controlled termination trials to evaluate treatment response and potential dependence phenomena [Hackenberg et al., 1985]. At any rate, benzodiazepines should only be prescribed after a careful evaluation of the patient and at the minimal effective dose over limited periods of time, in order to diminish the danger of dependence.

In conclusion, the results of this large-scale study suggest better efficacy of cloxazolam as compared to bromazepam on anxiety symptoms as well as on the associated sleep disturbances and depressed mood. The global tolerance of cloxazolam is also better, particularly with less muscle-relaxant side effects. 


\section{Acknowledgments}

We are grateful to Christiaens Laboratory, Brussels (Ch. Chatelle and L. Dodion) for help in the realization of the study; to all Belgian psychiatrists who collaborated in the study: Drs. Acke, Adriaensen, Aerts, Antoine, Baonville, Bataille, Bauloye-Dusaucy, Beckers, Bellens, Bergé, Bergen, Bertrand, Beusen, Biart, Bleeker, Block, Boeykens, Bogaerts, Bogaerts, Bollen, Bongaerts, Botte, Bourgeois, Brouckaert, Bruneel, Bruynooghe, Bryan, Casteleyn, Cerfontaine, Collin, Corens, Crochelet, Csizmadia, Daneels, Darge, Darimont, Deberdt, Debruyne, Delbeke, Delbergue, De Fleur, De Maere, Demeulemeester, De Munter, De Mol, De Nayer, Denis, Dericq, De Roover, De Smet, De Snijder, Deville, Devooght, De Wilde, De Wit, Dewulf, Dhaene, Dieudonné, Diricq, Dom, Dompas, Du Four, Dufour, Eeckhout, Elens, Evrard, Floris, Fontaine, Fortemps, Fraipont, Frederix, Gabriel, Gabriels, Gallez, Geens, Geerts, GérardVandenhove, Gernay, Gernay, Gillet, Guirgeas, Godfroid, Grosjean, Hannes, Hariga, Hebrecht, Hellinckx, Hens, Huygens, Ieven, Jansegers, Jocquet, Jonckheer, Jonckheere, Jorens, Kempeneers, Krahel, Krahel, Kindts, Leclercq, Lenaers, Leunen, Lindemans, Linhart, Lodewyck, Malfroid, Marganne, Martens, Meersman, Mertens, Mesotten, Meurice, Michotte, Minne, Mol, Mols, Mommaerts, Monte, Morreel, Mottard, Mouton, Nguyen, Nies, Noel, Nuyts, Padt, Parent, Peeters, Peeters, Piessens, Pirson, Posner, Restiau, Ringoet, Rombaut, Roose, Rossignol, Rousseau, Ruelens, Saey, Samain, Seghers, Sieben, Simon, Squelart, Stillemans, Suy, Taeymans, Tanghe, Teucq, Thiry, Triau, Trillet, Triffaux, Troisfontaines, Tuyls, Uytdenhoef, Van Acker, Van Assche, Van Audenrode, Van Buggenhout, Van Cauwenberghe, Van Daele, Van de Casteele, Vande Gaer, Van de Mosselaer, Van den Berghe, Vande Reyd, Van Elsacker, Van Haute, Van Landegem, Van Melkebeek, Van Moffaert, Vanhakendover, Van Ooteghem, Van Renynghe, Van Rieth, Van Velthoven, Verbeke, Verboogen, Verdee, Vereecken, Verhaeghe, Vermeylen, Vervarcke, Volcke, Wauters, Willemse, Wingender, Xhenseval, Zombek, Zwartenbroeckx, and to $\mathrm{Ch}$. Gayetot for her secretarial assistance.

\section{References}

Aitken, R.C.B.: Measurement of feelings using visual analogue scales. Proc. R. Soc. Med. 62: 989-993 (1969).

Ansseau, M.; Doumont, A.; Cerfontaine, J.L.; Mantanus, H.; Rousseau, J.C.; Timsit-Berthier, M.: Self-reports of anxiety level and EEG changes after a single dose of benzodiazepines. Doubleblind comparison of two forms of oxazepam. Neuropsychobiology 12: 255-259 (1984a).

Ansseau, M.; Doumont, A.; Diricq, St.: Methodology required to show clinical differences between benzodiazepines. Curr. med. Res. 8: suppl. 4, pp. 108-114 (1984b).

Ansseau, M.; Doumont, A.; Thiry, D.; von Frenckell, R.; Collard, J.: Initial study of methylclonazepam in generalized anxiety disorder. Evidence for greater power in the cross-over design. Psychopharmacology 87: 130-135 (1985).
Bellantuono, C.; Reggi, V.; Tognoni, G.; Garattini, S.: Benzodiazepines: Clinical pharmacology and therapeutic use. Drugs 19 . 195-219 (1980).

Bond, A.; Lader, M.: The use of analogue scales in rating subjective feelings. Br. J. med. Psychol. 47: 211-218 (1974).

Figueira, L.M.; Paes de Sousa, M.; Claudio, V.; Camara Pestana, L.; Quelhas, C.: On psychomotor performance under benzodiazepines. Acta psiquiat. port. 33: 59-64 (1987).

Fischer-Cornelssen, K.A.: Multicenter trials and complementary studies of cloxazolam, a new anxiolytic drug. ArzneimittelForsch. 31: 1757-1765 (1981).

Fontaine, R.; Annable, L,; Beaudry, P.; Mercier, P.; Chouinard, G.: Efficacy and withdrawal of two potent benzodiazepines: bromazepam and lorazepam. Psychopharmacol. Bull, 21: 91-92 (1985).

Fontaine, R.; Annable, L.; Chouinard, G.; Ogilvie, R.I.: Bromazepam and diazepam in generalized anxiety: a placebo-controlled study with measurement of drug plasma concentrations. J. clin. Psychopharmacol. 3: 80-87 (1983).

Hackenberg, B.; Fleischhaker, W.; Schubert, H.: Langzeitbehandlung mit Cloxazolam. Eine Studie über 4 Jahre. Therapiewoche Schweiz 1: 555-560 (1985).

Hamilton, M.: The assessment of anxiety states by ratings. $\mathrm{Br} . \mathrm{J}$. med. Psychol. 32: 50-55 (1959).

Kamioka, T.; Takagi, H.; Kobayashi, S.; Suzuki, Y.: Pharmacological studies on 10-chloro-11b-(2-chlorophenyl)-2,3,5,6,7,11bhexahydrobenzo(6,7) - 1,4 - diazepino $(5,4 b)$ - oxazol - 6 - one (CS370), a new psychosedative agent. Arzneimittel-Forsch. 22:884891 (1972).

Kesson, C.M.; Gray, J.M.B.; Lawson, D.H.: Benzodiazepine drugs in general medical patients. Br. med. J. $i$ : 680-682 (1976).

Lavene, D.; Abriol, C.; Guerret, M.; Kiechel, J.R.; Lallemand, A.; Rulliere, R.: Etude pharmacocinétique du cloxazolam après administration à dose unique et itérative chez l'homme. Thérapie 35: 533-543 (1980).

Sellers, E.M.: Clinical pharmacology and therapeutics of benzodiazepines. Can. med. Ass. J. 118: 1533-1538 (1978).

Wheatley, D.: Buspirone: multicenter efficacy study. J. clin. Psychiat. 43: 92-94 (1982).

Zmorski, Th.; Fischer-Cornelssen, K.A.: Klinische Erfahrungen mit dem Anxiolytikum der neuen Generation: Cloxazolam - Eine Doppelblindstudie. Praxis 74: 728-734 (1985).

Marc Ansseau, MD, PhD

Psychiatric Unit

CHU du Sart Tilman

B-4000 Liège (Belgium) 